\title{
The course of health-related quality of life from diagnosis to two years follow-up in patients with oropharyngeal cancer: does HPV status matter?
}

\author{
Laura H. A. Korsten ${ }^{1,2} \cdot$ Femke Jansen ${ }^{1,2,3,4} \cdot$ Birgit I. Lissenberg-Witte $^{5}$ - Marije Vergeer ${ }^{6}$ Ruud H. Brakenhoff ${ }^{1,2}$. \\ C. René Leemans ${ }^{1,2}$. Irma M. Verdonck-de Leeuw ${ }^{1,2,3,4}$ (i)
}

Received: 1 September 2020 / Accepted: 3 December 2020 / Published online: 17 January 2021

(C) The Author(s) 2021

\begin{abstract}
Purpose To investigate the course of health-related quality of life (HRQOL) from diagnosis to 2 years follow-up among patients with oropharyngeal cancer (OPSCC), in relation to human papilloma virus (HPV) status.

Methods This study included 270 OPSCC patients. Age, sex, tumor sublocation, tumor stage, HPV status, treatment modality, comorbidity, smoking, and alcohol use were retrieved from medical records. HPV status was positive when p16 and HPV DNA tests were both positive. HRQOL was assessed using the EORTC QLQ-C30/QLQ-H\&N35 pretreatment and at 6 weeks, 6, 12 , 18, and 24 months after treatment. To compare the course of HRQOL between patients with an HPV-positive versus HPVnegative tumor, linear and logistic mixed models were used.

Results Patients with an HPV-positive tumor (29\%) were more often male, diagnosed with a tumor of the tonsil or base of the tongue, treated with single treatment, had fewer comorbidities, were less often current smokers and had lower alcohol consumption. Adjusted for confounders, the course of global quality of life, physical, role, and social functioning, fatigue, pain, insomnia, and appetite loss was significantly different: patients with an HPV-positive tumor scored better before treatment, worsened during treatment, and recovered better and faster at follow-up, compared to patients with an HPV-negative tumor. The course of emotional functioning and oral pain was also significantly different between the two groups, but with other trajectories.

Conclusion The course of HRQOL is different in patients with an HPV-positive tumor versus an HPV-negative tumor, adjusted for sociodemographic, clinical, and lifestyle confounders.
\end{abstract}

Keywords Head and neck cancer $\cdot$ Human papilloma virus $\cdot \mathrm{HPV} \cdot$ Health-related quality of life $\cdot$ Oropharyngeal cancer $\cdot$ Cohort study

Irma M. Verdonck-de Leeuw

im.verdonck@amsterdamumc.nl

1 Department of Otolaryngology-Head and Neck Surgery, Amsterdam UMC, Vrije Universiteit Amsterdam, P.O. Box 7057, 1007, MB Amsterdam, the Netherlands

2 Cancer Center Amsterdam (CCA), Amsterdam, Netherlands

3 Amsterdam Public Health research institute, Amsterdam, Netherlands

4 Department of Clinical, Neuro- and Developmental Psychology, Amsterdam Public Health research institute, Vrije Universiteit Amsterdam, Amsterdam, the Netherlands

5 Amsterdam UMC, Vrije Universiteit Amsterdam, Department of Epidemiology and Biostatistics, Amsterdam, the Netherlands

6 Department of Radiation Oncology, Amsterdam UMC, Vrije Universiteit Amsterdam, Amsterdam, the Netherlands

\section{Introduction}

Head and neck cancer (HNSCC) is the sixth most common cancer worldwide [1]. The main risk factors for HNC are tobacco use and excessive alcohol consumption [2-4]. Also infection by the human papillomavirus (HPV) has been shown to be a risk factor in developing $\mathrm{HNC}$, especially in oropharyngeal carcinoma (OPSCC) $[5,6]$. In clinical practice, patients with an HPV-positive OPSCC respond better to treatment and seem to report better health-related quality of life (HRQOL), compared to patients with an HPV-negative OPSCC. Previous studies showed that HNSCC patients with an HPV-positive OPSCC have a better prognosis and survival rate is higher as compared to patients with an HPV-negative tumor [7-11]. Previous literature reviews on HRQOL in OPSCC patients $[12,13]$ concluded that subanalyses 
investigating the association between HRQOL and HPV status were not possible because the inclusion periods of most studies predated regular HPV testing. At present, we found ten studies that investigated HPV status in relation to HRQOL among HNSCC patients [14-23]. Findings from these studies suggest that HRQOL of patients with an HPV-positive tumor (compared to those diagnosed with an HPV-negative tumor) may be better before treatment, deteriorates much more during treatment, and recovers better from three months follow-up and beyond, but this pattern may be confounded by sociodemographic, clinical, and lifestyle factors [17]. Obviously, there is still a need for more research into the association between HPV status and HRQOL in OPSCC patients. Therefore, the aim of the present study was to investigate the course of HRQOL (as measured with the EORTC QLQ-C30 and QLQ-H\&N35) among OPSCC patients in relation to HPV status, from pretreatment to 24month follow-up, taking into account possible sociodemographic and clinical confounders. The results of this study are highly relevant for clinical practice to tailor information and supportive care in a personalized way taking HPV status into account.

\section{Materials and methods}

\section{Study population}

The study population consisted of patients diagnosed with primary squamous cell carcinoma of the mucosal surfaces of the oropharynx (OPSCC) and treated with curative intent between January 1999 and January 2011 at the Amsterdam UMC, location VUmc in Amsterdam. Exclusion criteria were distant metastases, second primary tumors, previous surgery or radiotherapy for $\mathrm{HNSCC}$, brachytherapy, serious cognitive impairment or lack of basic knowledge of the Dutch language. We also excluded patients who did not complete pretreatment HRQOL questionnaires and of whom HPV status was not assessed.

Sociodemographic (age, sex), clinical (comorbidity (none, mild, moderate, severe), tumor sublocation: tonsil, base of tongue, soft palate/uvula, other oropharyngeal locations), TNM tumor stage (stage I - IV according to the American Joint Committee on Cancer 7th edition) [24], HPV status (positive, negative), treatment modality (categorized as single (surgery or radiotherapy) or combination (surgery and (chemo) radiotherapy, or chemoradiation)), and lifestyle (smoking (pack years), and alcohol use (units per year)) variables were retrieved from medical records. Comorbidity was assessed using the Adult Comorbidity Scale-27 (ACE-27), a validated instrument with four grades of comorbidity (none, mild, moderate, or severe) [25]. Tumor biopsies of all patients were tested for HPV according to the validated test algorithm for
HPV-detection, consisting of $\mathrm{p} 16^{\mathrm{INK} 4 \mathrm{~A}}$ immunostaining followed by high risk HPV DNA-detection on formalin-fixed paraffin-embedded (FFPE) tumor specimen [26]. HPV status was scored as HPV-positive when p16 and HPV DNA tests were both positive. Treatment modality was categorized into single treatment (surgery or radiotherapy alone) versus combination treatment (surgery, radiotherapy, chemotherapy).

HRQOL data was collected as part of standard clinical care. Since 1999 (department of Radiotherapy) and 2016 (department of Otolaryngology-Head and Neck Surgery), HNC patients are asked to complete patient-reported outcomes measures (PROMs) on HRQOL using a paper-and-pencil version of the PROMs and a touch screen computer-assisted data collection system called OncoQuest respectively. Patients are asked to complete these PROMs in the clinic before start of treatment and at every follow-up visit at one of the two departments. Information on durable usage of these PROMs in our clinic can be found elsewhere [27]. All patients were asked for informed consent to use their data for scientific research. Patients were only included in this study when they provided such informed consent. According to the Dutch Medical Research Involving Human Subjects Act, ethical approval was not necessary, because patients were not subjected to procedures or required to follow rules of behavior.

\section{HRQOL outcome measures}

HRQOL was assessed using the EORTC QLQ-C30 and EORTC QLQ-H\&N35. The 30-item EORTC QLQ-C30 is a generic HRQOL questionnaire that consists of nine domains and six single items. These nine domains include global quality of life, physical functioning, role functioning, emotional functioning, cognitive functioning, social functioning, fatigue, nausea and vomiting, and pain. Single items encompass: dyspnea, insomnia, appetite loss, constipation, diarrhea, and financial difficulties. The scores of the QLQ-C30 are linearly transformed to a scale of $0-100$, with a higher score suggesting a higher (i.e., more positive) level of functioning or global HRQOL, or a higher (i.e., more negative) level of symptoms or problems $[28,29]$. The EORTC QLQ-H\&N35 is an HNCspecific HRQOL questionnaire that consists of seven scales and eleven single items. The scales include oral pain, swallowing, senses, speech, social eating, social contact, and sexuality. The single items consists of items about problems with teeth, problem with opening the mouth, dry mouth, sticky saliva, coughing, feeling ill, use of painkillers, nutritional supplements, feeding tube, losing weight, or gaining weight. The scores of the QLQ-H\&N35 are linearly transformed to a scale of $0-100$, with a higher score suggesting a higher (i.e., more negative) level of symptoms or problems [29]. Patients were asked to complete the questionnaires at baseline (pretreatment) and at 6 weeks and 6,12, 18, and 24 months after treatment. 


\section{Statistical analyses}

Descriptive statistics were generated for the range of patient characteristics and outcome variables. Chi-square tests were used to examine differences between patients with an HPVpositive versus HPV-negative tumor, with respect to sex, comorbidity, tumor sublocation, tumor stage, treatment modality, smoking, and alcohol use. Age was compared with the independent samples $t$ test. To compare the longitudinal course of HRQOL between patients with an HPV-positive versus HPV-negative tumor, linear, and logistic mixed models were used with fixed effects for group (HPV-positive or HPVnegative) and measurement (pretreatment and at 6 weeks and $6,12,18$, and 24 months after treatment) and their two-way interaction, and a random effect for subject (patients with an OPSCC tumor). To investigate potential confounding (sociodemographic (age, sex), clinical (comorbidity, tumor sublocation, tumor stage, treatment modality), lifestyle (smoking and alcohol use)) variables, these variables were included one by one in the analyses. Variables associated with HPV status and HRQOL that changed the regression coefficient of HPV status with more than $10 \%$ were included in the final model (starting with the strongest confounder) [30]. Statistical analyses were performed in SPSS 22.0 for Windows. A $p$ value of 0.05 or less was considered statistically significant and indicates a significant different trajectory of quality of life over time for HPV-positive versus HPVnegative patients.

\section{Results}

\section{Study sample}

In total, 270 patients met the in- and exclusion criteria, of whom 29\% had an HPV-positive tumor (78/270) (Fig. 1). Patient characteristics are shown in Table 1. There were significant differences, pretreatment, between patients with HPV-positive versus HPV-negative tumors with respect to sex, comorbidity, treatment modality, smoking, and alcohol consumption. Patients with an HPV-positive tumor were significantly more often male, had fewer comorbidities, were more often diagnosed with a tumor of the tonsil or base of the tongue, were more often treated with single treatment, were less often current smokers and had lower alcohol consumption.

\section{The course of HRQOL in relation to HPV status}

The course of the HRQOL scores (mean and standard deviation) from pre-treatment to 24 months follow-up on the various subscales of the EORTC QLQ-C30 and QLQ-H\&N35 is presented in Table 2.
Multivariate mixed model analyses revealed that, after correcting for confounders (sex, comorbidity, tumor stage, treatment modality), the course of HRQOL was significantly different between patients with an HPV-positive tumor versus patients with an HPV-negative tumor, regarding global quality of life physical functioning, role functioning, emotional functioning, social functioning, fatigue, pain, insomnia, appetite loss (EORTC QLQ-C30, Table 3), and oral pain (EORTC QLQ-H\&N35) (Table 4).

Three trajectories were observed (unadjusted). With respect to global quality of life, physical functioning, role functioning, social functioning, fatigue, pain, insomnia, and appetite loss, patients with an HPV-positive tumor scored equal or better before treatment, worsened more during treatment, and recovered better and faster at follow-up compared to patients with an HPV-negative tumor (Fig. 2). A second trajectory was seen for emotional functioning: mean scores were equal at baseline, and at 6 weeks after treatment and 3 months follow-up, but scores improved more in patients treated for an HPV-positive tumor at 6,12, and 24 months follow-up compared to those treated for an HPV-negative tumor. A third trajectory was observed for oral pain (EORTC QLQH\&N35). In patients with an HPV-positive tumor (compared to patients with an HPV-negative tumor) mean oral pain score was lower before treatment and 6 weeks after treatment, was similar at 3 months follow-up, lower again at 6 and 12 months follow-up, and similar at 24 months follow-up.

\section{Discussion}

In this study, we found significant differences in the course of HRQOL from diagnosis to 2 years follow-up between OPSCC patients with an HPV-positive tumor compared to those with an HPV-negative tumor, when adjusted for confounders as sex, comorbidity, tumor sublocation, tumor stage, and treatment modality. These differences concerned the course of global quality of life, physical, emotional, social, and role functioning, and the symptoms fatigue, pain, insomnia, and appetite loss (EORTC QLQ-C30 subscales) and oral pain (EORTC QLQ-H\&N35 subscale). No differences between both groups were found for the course of cognitive functioning, nausea/vomiting, dyspnea, constipation, diarrhea, financial difficulties (EORTC QLQ-C30 subscales), and, except for oral pain, all other HNC-specific symptoms (EORTC QLQ-H\&N35 subscales).

Of the ten studies that investigated HPV status in relation to HRQOL among HNSCC patients [14-23], six investigated the association between HPV status and HRQOL before treatment [14, 17, 19, 21-23]. Two studies reported that patients diagnosed with an HPV-positive OPSCC had better HRQOL compared to patients diagnosed with an HPV-negative tumor $[19,21]$. These two studies did not adjust for possible 


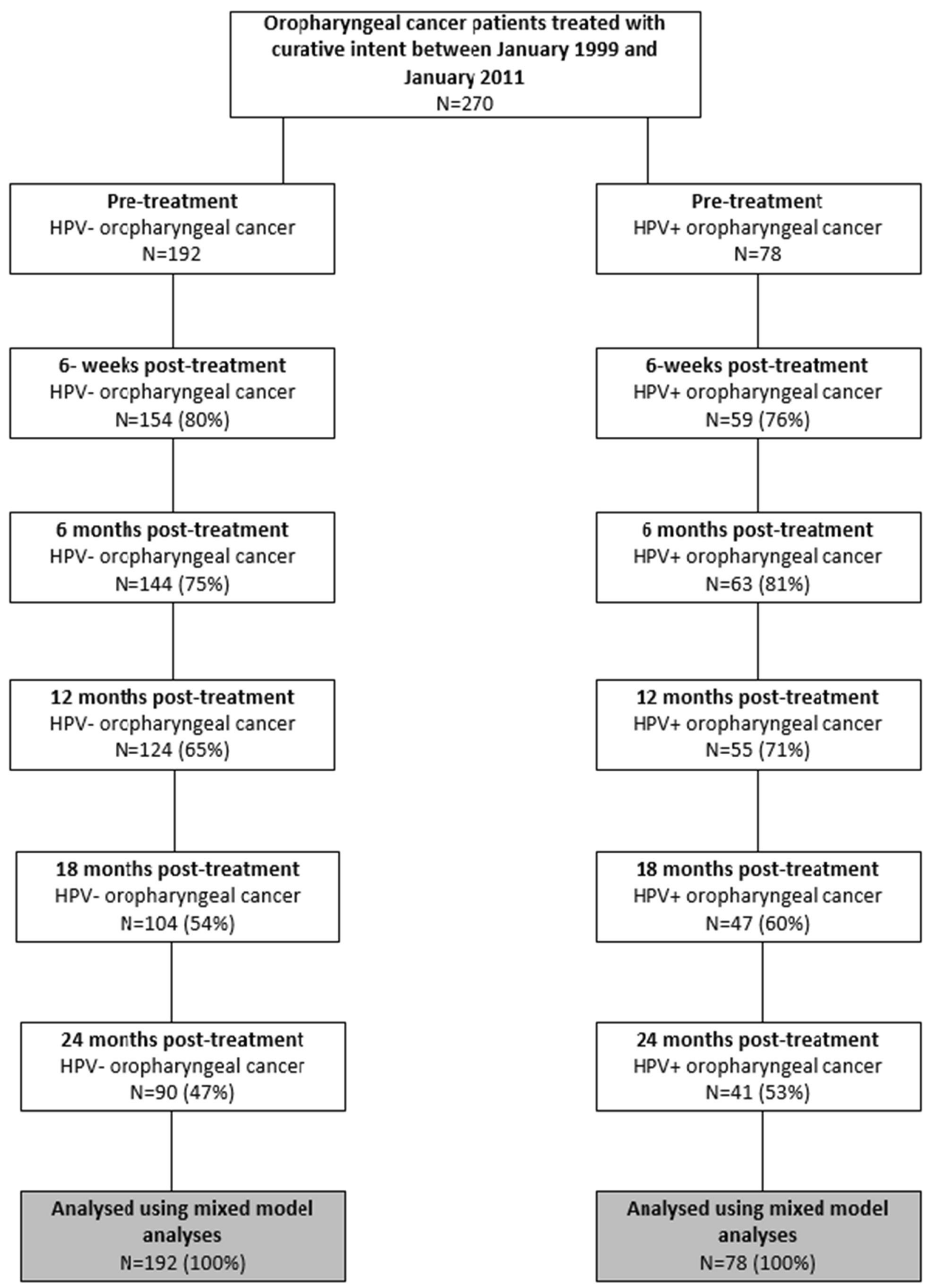

Fig. 1 Flow diagram 
Table 1 Overview of patient characteristics $(n=270)$ in relation to HPV-status of the tumor

\begin{tabular}{|c|c|c|c|c|c|c|}
\hline & & \multicolumn{4}{|l|}{ HPV-status } & \multirow[t]{2}{*}{$p$ value } \\
\hline & & Negative $N=192$ & $\%(71.1)$ & Positive $N=78$ & $\%(28.9)$ & \\
\hline \multicolumn{2}{|l|}{ Age, years Mean age (SD) } & $59.9(8.7)$ & & $59.9(8.2)$ & & 0.95 \\
\hline \multirow[t]{2}{*}{ Sex } & Male & 120 & $62.5 \%$ & 59 & $75.6 \%$ & 0.038 \\
\hline & Female & 72 & $37.5 \%$ & 19 & $24.4 \%$ & \\
\hline \multirow[t]{4}{*}{ Comorbidity } & None & 65 & $33.9 \%$ & 42 & $53.8 \%$ & 0.026 \\
\hline & Mild & 59 & $30.7 \%$ & 17 & $21.8 \%$ & \\
\hline & Moderate & 54 & $28.1 \%$ & 15 & $19.2 \%$ & \\
\hline & Severe & 14 & $7.3 \%$ & 4 & $5.1 \%$ & \\
\hline \multirow[t]{3}{*}{ Smoking } & No smoking & 17 & $8.9 \%$ & 33 & $42.9 \%$ & $<0.001$ \\
\hline & $1-24$ pack years & 24 & $12.6 \%$ & 18 & $23.4 \%$ & \\
\hline & $>24$ pack years & 150 & $78.5 \%$ & 26 & $33.8 \%$ & \\
\hline \multirow[t]{3}{*}{ Alcohol use } & No alcohol use & 19 & $10.0 \%$ & 24 & $31.2 \%$ & $<0.001$ \\
\hline & $1-149$ units per year & 41 & $21.6 \%$ & 29 & $37.7 \%$ & \\
\hline & $>149$ units per year & 130 & $68.4 \%$ & 24 & $31.2 \%$ & \\
\hline \multirow[t]{4}{*}{ Tumor location } & Base of tongue & 44 & $22.9 \%$ & 23 & $29.5 \%$ & $<0.001$ \\
\hline & Soft palate & 37 & $19.3 \%$ & 4 & $5.1 \%$ & \\
\hline & Tonsil & 74 & $38.5 \%$ & 48 & $61.5 \%$ & \\
\hline & Oropharynx nos & 37 & $19.3 \%$ & 3 & $3.8 \%$ & \\
\hline \multirow[t]{4}{*}{ TNM classification } & Stage I & 27 & $14.1 \%$ & 10 & $12.8 \%$ & 0.24 \\
\hline & Stage II & 47 & $24.5 \%$ & 14 & $17.9 \%$ & \\
\hline & Stage III & 45 & $23.4 \%$ & 14 & $17.9 \%$ & \\
\hline & Stage IV A-B & 73 & $38 \%$ & 40 & $51.3 \%$ & \\
\hline \multirow[t]{2}{*}{ Treatment } & Single treatment* & 103 & $53.6 \%$ & 25 & $32.1 \%$ & 0.001 \\
\hline & Combination treatment & 89 & $46.4 \%$ & 53 & $67.9 \%$ & \\
\hline
\end{tabular}

$H P V$ human papilloma virus; $S D$ standard deviation; nos not otherwise specified

*This comprised RT: $n=99, \operatorname{surg} n=4$

sociodemographic, clinical, or lifestyle confounders. Three other studies showed no differences between the two groups in HRQOL before treatment, when adjusting for possible confounders in multivariate analyses [14, 17, 22]. One study focusing on fatigue reported that patients with an HPV-positive OPSCC had less fatigue at baseline, when adjusting for confounders.

All ten studies investigated the association between HPV status and HRQOL during or after treatment or at follow-up. One study reported worse HRQOL in the two last weeks of treatment in patients with an HPV-positive tumor compared to those treated for an HPV-negative tumor [21]. Several studies reported better HRQOL outcome at 2-3 months [19], 6 months [19], 12 months [17, 19, 21], and beyond 1-year follow-up [16, 17, 19, 21] in patients treated for an HPVpositive tumor compared to those treated for an HPVnegative tumor. In contrast, several other studies reported no significant differences in HRQOL between the two groups posttreatment [20], at 2-3 months [17], 6 months [17], 12 months [15], or beyond 1-year follow-up [18]. In all these analyses, possible sociodemographic, clinical, or lifestyle confounders were not adjusted for. Three studies did adjust for possible confounders [14, 22, 23]. A study among 112 OPSCC patients treated with free-flap reconstructive surgery reported that speech intelligibility and swallowing safety do not seem to differ between both groups at baseline or 6 or 12 months follow-up, when adjusted for age, sex, and tumor stage [22]. The same holds for HRQOL, except for social functioning which was better at follow-up in patients treated with an HPV-positive tumor [22]. Sharma et al. [14] reported similar findings on the course of the overall score of the HNCspecific University of Washington Quality of Life questionnaire from baseline to 1-year follow-up: patients with an HPV-positive tumor scored better before treatment, worsened much more during treatment, and recovered better and faster at follow-up compared to patients with an HPV-negative tumor. However, when they adjusted for possible confounding factors (age, sex, race, tumor subsite and stage, treatment modality, comorbidity, smoking, alcohol use), this difference was no longer significant. This may be explained by the fact that they used an overall score of the HNC-specific HRQOL questionnaire, which matches the findings in the present study that 


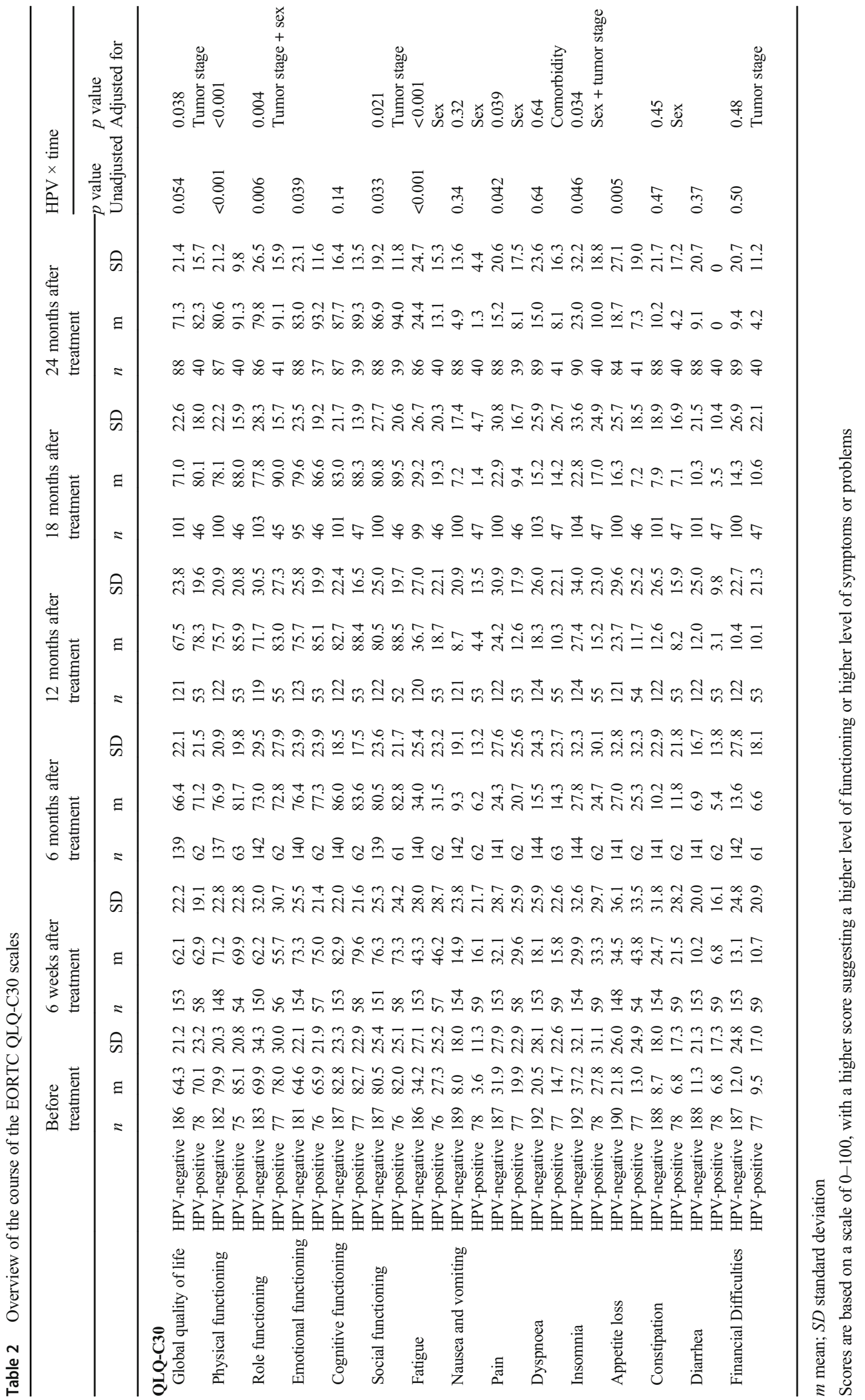


Table 3 Overview of the course of the EORTC QLQ-H\&N35 scales

\begin{tabular}{|c|c|c|c|c|c|c|c|c|c|c|c|c|c|c|c|c|c|c|c|}
\hline & & \multicolumn{3}{|c|}{$\begin{array}{l}\text { Before } \\
\text { treatment }\end{array}$} & \multicolumn{3}{|c|}{$\begin{array}{l}6 \text { weeks after } \\
\text { treatment }\end{array}$} & \multicolumn{3}{|c|}{$\begin{array}{l}6 \text { months after } \\
\text { treatment }\end{array}$} & \multicolumn{3}{|c|}{$\begin{array}{l}12 \text { months after } \\
\text { treatment }\end{array}$} & \multicolumn{3}{|c|}{$\begin{array}{l}18 \text { months after } \\
\text { treatment }\end{array}$} & \multicolumn{3}{|c|}{$\begin{array}{l}24 \text { months } \\
\text { after treatment }\end{array}$} \\
\hline & & $n$ & $\mathrm{~m}$ & $\mathrm{SD}$ & $n$ & $\mathrm{~m}$ & SD & $n$ & $\mathrm{~m}$ & $\mathrm{SD}$ & $n$ & $\mathrm{~m}$ & $\mathrm{SD}$ & $n$ & $\mathrm{~m}$ & $\mathrm{SD}$ & $n$ & $\mathrm{~m}$ & SD \\
\hline \multicolumn{20}{|l|}{ QLQ-H\&N35 } \\
\hline \multirow[t]{2}{*}{ Oral pain } & HPV-negative & 186 & 37.0 & 27.7 & 150 & 34.7 & 29.7 & 141 & 32.0 & 26.7 & 122 & 32.9 & 26.4 & 98 & 34.2 & 28.1 & 86 & 28.0 & 24. \\
\hline & $\mathrm{HPV}-$ & 75 & 22.3 & 23.8 & 57 & 24.9 & 21.0 & 60 & 31.4 & 26.5 & 53 & 23.3 & 23.2 & 46 & 22.1 & 23.4 & 40 & 25.2 & 23. \\
\hline \multirow[t]{2}{*}{ Swallowing } & $\mathrm{HPV}$ & 162 & 27.8 & 24.6 & 136 & 34.9 & 29.8 & 129 & 31.1 & 26.9 & 104 & 30.3 & 25.9 & 90 & 33.1 & 27.2 & 82 & 30.0 & 28. \\
\hline & $\mathrm{HPV}-1$ & 72 & 21.8 & 25.7 & 55 & 29.5 & 27.3 & 56 & 35.1 & 29.9 & 46 & 27.2 & 28.7 & 41 & 25.6 & 25.9 & 37 & 22.7 & 21. \\
\hline \multirow[t]{2}{*}{ Senses } & HPV- & 184 & 18.7 & 24.4 & 146 & 22.7 & 27.5 & 142 & 24.3 & 27.8 & 116 & 26.3 & 28.0 & 101 & 21.6 & 27.6 & 89 & 24.0 & 26.0 \\
\hline & HPV-positive & 77 & 16.5 & 24.7 & 57 & 22.2 & 25.5 & 59 & 22.3 & 26.0 & 51 & 17.2 & 21.7 & 45 & 19.3 & 23.8 & 41 & 16.7 & 22. \\
\hline \multirow[t]{2}{*}{ Speech } & HPV-negative & 182 & 18.3 & 20.7 & 145 & 22.3 & 24.5 & 139 & 19.0 & 22.2 & 117 & 19.5 & 20.1 & 97 & 20.5 & 22.9 & 86 & 17.8 & 22. \\
\hline & $\mathrm{HP}$ & 76 & 12.3 & 20.0 & 58 & 16.7 & 24.0 & 61 & 19.9 & 23.4 & 54 & 14.8 & 18.3 & 47 & 16.3 & 22.2 & 41 & 11.4 & 17.8 \\
\hline \multirow[t]{2}{*}{ Social eating } & $\mathrm{HPV}$ & 168 & 23.9 & 24.2 & 139 & 30.8 & 29.6 & 126 & 30.8 & 26.5 & 101 & 32.3 & 27.0 & 87 & 30.3 & 25.9 & 77 & 31.0 & 29. \\
\hline & HPV & 72 & 21.5 & 28.4 & 54 & 28.9 & 27.7 & 53 & 28.3 & 28.4 & 46 & 23.2 & 28.7 & 43 & 24.8 & 26.1 & 38 & 18.0 & 23. \\
\hline \multirow[t]{2}{*}{ Social contact } & $\mathrm{HPY}$ & 172 & 7.4 & 12.0 & 140 & 11.6 & 17.9 & 134 & 12.4 & 19.6 & 108 & 11.5 & 18.4 & 95 & 10.2 & 15.0 & 82 & 9.7 & 16. \\
\hline & $\mathrm{HPV}-1$ & 72 & 5.5 & 15.0 & 56 & 9.4 & 18.7 & 60 & 10.3 & 19.5 & 52 & 4.6 & 11.2 & 47 & 5.5 & 15.8 & 39 & 3.8 & 6.1 \\
\hline \multirow[t]{2}{*}{ Sexuality } & HP & 148 & 31.9 & 35.7 & 117 & 34.3 & 37.7 & 104 & 27.6 & 35.4 & 94 & 31.2 & 32.1 & 78 & 30.8 & 35.6 & 63 & 34.1 & 35.8 \\
\hline & HPV- & 65 & 23.6 & 33.8 & 49 & 32.3 & 34.8 & 56 & 31.0 & 35.7 & 48 & 28.5 & 35.4 & 40 & 25.4 & 32.9 & 39 & 21.0 & 28. \\
\hline \multirow[t]{2}{*}{ Problems with teeth } & ive & 178 & 22.8 & 32.3 & 138 & 27.5 & 36.0 & 133 & 26.3 & 34.8 & 107 & 21.5 & 28.7 & 93 & 22.6 & 31.5 & 87 & 20.3 & 29. \\
\hline & $\mathrm{HPV}-1$ & 76 & 14.0 & 27.9 & 55 & 14.5 & 27.0 & 60 & 15.6 & 29.1 & 51 & 15.0 & 26.1 & 46 & 14.5 & 25.0 & 40 & 13.3 & 27. \\
\hline \multirow[t]{2}{*}{ Problems opening mouth } & $\mathrm{HPV}_{-1}$ & 188 & 34.6 & 34.9 & 152 & 36.4 & 36.7 & 142 & 35.9 & 35.7 & 122 & 41.3 & 34.8 & 102 & 35.0 & 37.0 & 90 & 35.9 & 35. \\
\hline & HPV-po & 78 & 27.8 & 32.9 & 58 & 29.9 & 35.7 & 61 & 37.2 & 35.0 & 53 & 29.6 & 33.8 & 47 & 29.1 & 35.2 & 41 & 26.8 & 31. \\
\hline \multirow[t]{2}{*}{ Dry mouth } & HPV-negative & 190 & 45.4 & 36.4 & 152 & 51.5 & 36.8 & 142 & 53.8 & 37.2 & 120 & 53.3 & 35.7 & 102 & 50.3 & 36.0 & 89 & 51.7 & 40. \\
\hline & HPV-po & 78 & 43.2 & 36.5 & 58 & 62.1 & 33.3 & 61 & 60.7 & 51.1 & 54 & 50.0 & 37.1 & 47 & 48.9 & 36.7 & 41 & 41.5 & 28. \\
\hline \multirow[t]{2}{*}{ Sticky saliva } & HPV-negative & 188 & 41.8 & 33.4 & 150 & 48.9 & 37.2 & 137 & 49.6 & 64.6 & 118 & 50.8 & 35.3 & 98 & 46.9 & 35.8 & 85 & 43.5 & 35. \\
\hline & $\mathrm{HPV}_{-1}$ & 78 & 35.5 & 35.0 & 55 & 49.1 & 35.1 & 61 & 41.0 & 35.2 & 51 & 40.5 & 37.3 & 46 & 39.1 & 35.3 & 40 & 36.7 & 32. \\
\hline \multirow[t]{2}{*}{ Coughed } & $\mathrm{HPV}^{-1}$ & 189 & 25.4 & 27.5 & 152 & 29.2 & 27.7 & 142 & 26.5 & 26.5 & 122 & 30.6 & 29.6 & 101 & 26.4 & 30.3 & 90 & 23.7 & 27. \\
\hline & HPV-p & 77 & 19.5 & 26.7 & 58 & 28.7 & 25.3 & 61 & 29.0 & 26.2 & 54 & 22.8 & 29.5 & 47 & 22.7 & 23.2 & 41 & 23.6 & 30. \\
\hline \multirow[t]{2}{*}{ Feeling ill } & HPV-negative & 189 & 17.8 & 25.6 & 152 & 20.0 & 28.5 & 142 & 16.4 & 26.6 & 121 & 19.8 & 29.7 & 102 & 19.0 & 29.9 & 90 & 16.3 & 27. \\
\hline & HPV-positive & 77 & 12.6 & 24.8 & 58 & 13.2 & 19.7 & 61 & 18.0 & 26.2 & 54 & 13.6 & 25.5 & 47 & 9.9 & 19.6 & 41 & 14.6 & 26. \\
\hline Painkillers & HPV-negative & 187 & 50.8 & 50.1 & 153 & 50.3 & 50.2 & 144 & 53.5 & 50.1 & 123 & 56.1 & 49.8 & 103 & 46.6 & 50.1 & 87 & 51.7 & 50. \\
\hline & HPV-positive & 75 & 33.3 & 47.5 & 58 & 36.2 & 48.5 & 61 & 44.3 & 50.1 & 54 & 38.9 & 49.2 & 47 & 36.2 & 48.6 & 41 & 46.3 & 50. \\
\hline Nutritional supplements & HPV-negative & 185 & 44.3 & 49.8 & 148 & 48.0 & 50.1 & 143 & 53.2 & 50.1 & 119 & 51.3 & 50.2 & 102 & 50.0 & 50.2 & 87 & 42.5 & 49. \\
\hline & HPV-positive & 74 & 36.5 & 48.5 & 58 & 39.7 & 49.3 & 62 & 40.3 & 49.5 & 54 & 29.6 & 46.1 & 46 & 32.4 & 47.4 & 41 & 26.8 & 44. \\
\hline Feeding tube & HPV-negative & 185 & 19.4 & 39.7 & 150 & 24.0 & 42.9 & 144 & 18.1 & 38.6 & 123 & 19.5 & 39.8 & 103 & 18.5 & 39.0 & 87 & 16.1 & 37. \\
\hline & HPV-positive & 75 & 14.7 & 35.6 & 58 & 22.4 & 42.1 & 62 & 24.2 & 43.2 & 53 & 28.3 & 45.5 & 47 & 14.9 & 36.0 & 41 & 9.8 & 30. \\
\hline Lost weight & HPV-negative & 184 & 31.0 & 46.4 & 151 & 37.8 & 48.6 & 142 & 38.7 & 53.1 & 123 & 29.3 & 45.7 & 100 & 37.0 & 48.5 & 87 & 33.3 & 47. \\
\hline & HPV-positive & 73 & 21.9 & 41.7 & 58 & 22.4 & 42.1 & 61 & 32.8 & 47.3 & 53 & 20.8 & 40.9 & 47 & 17.0 & 38.0 & 41 & 14.6 & 35. \\
\hline Gained weight & HPV-negative & 182 & 29.7 & 45.8 & 149 & 32.2 & 46.9 & 140 & 27.9 & 45.0 & 122 & 31.2 & 46.5 & 101 & 31.7 & 46.8 & 86 & 29.1 & 45. \\
\hline & HPV-positive & 72 & 31.9 & 47.0 & 58 & 31.0 & 46.7 & 60 & 26.7 & 44.6 & 53 & 30.2 & 46.3 & 47 & 29.8 & 46.2 & 41 & 22.0 & 41. \\
\hline
\end{tabular}

$m$ mean; $S D$ standard deviation

Scores are based on a scale of $0-100$, with a higher score suggesting a higher level of symptoms or problems

there were no significant differences between the two groups on the course of nearly all HNC symptoms (except oral pain). The course of oral pain in the present study was also significantly different between the groups but with a different trajectory: patients with HPV-positive OPSCC reported less oral pain before treatment and 6 weeks after treatment, similar scores at 3 months follow-up, less again at 6 and 12 months follow-up, and similar at 24 months follow-up, as compared to patients with HPV-negative OPSCC. This pattern is hard to understand. It may be a statistical anomaly although the 
Table 4 Results of mixed model analyses for all patients regarding the course of head and neck cancer-specific Quality of Life (EORTC QLQ-H\&N35) over time

\begin{tabular}{lll}
\hline & HPV $\times$ time $p$ value unadjusted & $p$ value adjusted \\
\hline Pain sex + alcohol use & 0.017 & 0.018 \\
Swallowing tumor stage & 0.20 & 0.19 \\
Senses - & 0.86 & \\
Speech tumor stage & 0.42 & 0.42 \\
Social eating tumor stage & 0.70 & 0.61 \\
Social contact tumor stage & 0.37 & 0.31 \\
Sexuality tumor stage + comorbidity & 0.43 & 0.38 \\
Problems with teeth tumor stage & 0.89 & 0.92 \\
Problems opening mouth treatment + tumor stage & 0.61 & 0.60 \\
Dry mouth sex + tumor stage & 0.19 & 0.15 \\
Sticky saliva tumor stage & 0.93 & 0.88 \\
Coughed tumor stage & 0.34 & 0.33 \\
Felt ill tumor stage & 0.30 & 0.27 \\
Painkillers sex + alcohol use + tumor stage & 0.83 & 0.94 \\
Nutritional supplements tumor stage & 0.76 & 0.65 \\
Feeding tube tumor stage & 0.30 & 0.30 \\
Lost weight - & 0.46 & \\
Gained weight - & 0.97 & \\
\hline
\end{tabular}

differences were also clinically relevant (difference of $>10$ points). It may also be caused by the nature of the EORTC QLQ-H\&N35 oral pain subscale which consists of 4 items related to pain in the mouth, pain in the jaw, soreness in the mouth, and a painful throat. More research on the association between HPV status and pain is needed. The third study that adjusted for confounders reported that in patients with an HPV-positive tumor fatigue increased more from baseline to 1-month follow-up but recovered better at 3 months follow-up compared to patients with an HPV-negative tumor [23].

In the "Introduction" section, based on these previous studies [14-23], we suggested that the course of HRQOL of patients with an HPV-positive tumor (compared to those diagnosed with an HPV-negative tumor) may be better before treatment, deteriorates much more during treatment, but recovers better from 3-month follow-up and beyond. In the current study, we showed that these different trajectories are present regarding physical, social, and role functioning, and the symptoms fatigue, pain, insomnia, and appetite loss, also when adjusted for sociodemographic, clinical, and lifestyle confounders.

Differences in the course of HRQOL between patients with an HPV-positive versus HPV-negative OPSCC, especially the deterioration shortly after treatment in HPV-positive patients, may be explained by acute toxicity. Ringash et al. [17] examined the rate of acute toxicity at 2 months after treatment by HPV status. Patients with HPV-positive tumors had a higher frequency of grade 2 to 4 toxicity for nausea, vomiting, and salivary changes. Although in the present study, the course of nausea and vomiting, sticky saliva, and xerostomia from baseline to 2 years follow-up was not significantly different, patients with HPV-positive tumors had worse scores regarding xerostomia at 6 weeks and 3 months follow-up. Ringash et al. [17] also found that asymptomatic neutrophil and $\mathrm{Hb}$ toxicities at 2 months follow-up were more frequent in patients with an HPV-negative tumor compared to those treated for an HPV-positive tumor. Also Fang et al. [23] reported that fatigue increased more from baseline to 1 month after radiotherapy but was significantly less at 3 months in patients with an HPV-positive tumor compared to those with an HPVnegative tumor, and this pattern was significantly associated with inflammation as measured with plasma sTNFR2. This may explain the findings in the present study that patients treated for an HPV-positive tumor in general recover better and faster from symptoms such as fatigue, pain, and insomnia, and that physical, role, social, and emotional functioning is better in the longer term, compared to patients treated for an HPV-negative tumor. However, more research is needed to unravel these complex associations.

Strength of this study was the study design with general cancer as well as HNC-specific HRQOL assessments from baseline up to 2 years after treatment among a large sample of patients with OPSCC only. Also, HPV status was tested based on p16 as well as HPV-DNA, in contrast to previous studies that used p16 as surrogate marker of HPV status only. In addition, several sociodemographic and clinical confounders were taken into account. We also investigated the role of possible lifestyle confounders (smoking and alcohol use before start of treatment), but this did not change the outcome and was not relevant to the significance of the results. 

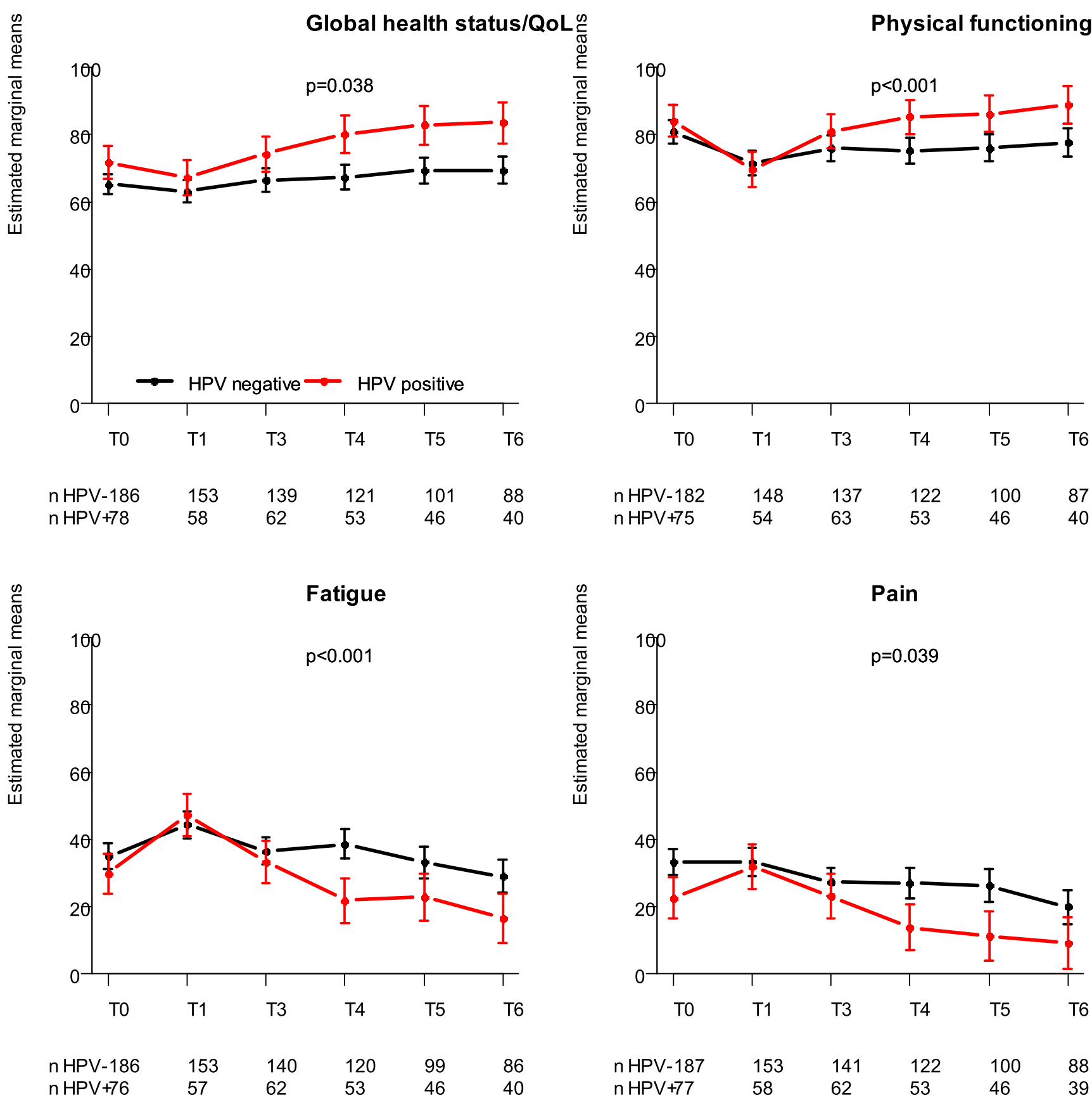

Fig. 2 Change over time for HPV-positive versus HPV-negative patients. Estimated marginal means - corrected

Further research is, however, warranted on the potential confounding role of continued smoking and alcohol use during follow-up, as well as other potential sociodemographic confounders such as education and living situation. These factors were not included in our study, which should be seen as a limitation. Another limitation of this study is that we excluded patients of whom HPV status was not known and those patients without pretreatment HRQOL data, which may have induced selection bias. Furthermore, our data represent a small proportion (estimated on 10-15\%) of the total number of OPSCC patients in the Netherlands. Due to the study design and privacy regulations, it was not possible to compare responders and nonresponders of this study. Another limitation is that the QOL data was acquired as part of routine clinical care and therefore depended on timing of the follow-up visits and was therefore not exactly at 6 weeks, 3, 6, 12, and 24 months follow-up. As a comparable time, window was used for both HPV+ and HPV- OPSCC patients, we, however, expect that this does not have influenced our findings. Another limitation is the existence of missing surveys due to death and, in minority, to loss to follow-up. Finally, a potential limitation of this study is that HRQQOL measured at the end 
of treatment was not taken into account while acute toxicities such as fatigue and appetite loss may be highest at this time point.

The findings in this study may contribute to the current discussion about treatment deescalation. Efforts to improve treatment outcome in this patient group should also focus on preventing HRQOL deterioration during and shortly after treatment when possible [31-34]. Furthermore, the results of this study are helpful in further advancing supportive care by providing information on the impact of OPSCC and its treatment on HRQOL and referring patients to supportive care, tailored to the needs of OPSCC patients with HPV-positive and those with HPV-negative tumors.

\section{Conclusion}

Among OPSCC patients, the trajectory of the course of HRQOL is significantly different in patients with an HPVpositive versus an HPV-negative tumor, when adjusted for sociodemographic and clinical confounders. Regarding global quality of life, physical functioning, role functioning, social functioning, fatigue, pain, insomnia, and appetite loss, patients with HPV-positive OPSCC score better before treatment, deteriorate more during and shortly after treatment, and recover better and faster at follow-up, compared to patients with HPVnegative OPSCC. Furthermore the course of emotional functioning and oral pain is significantly different between the two groups, but with other trajectories.

Authors' contributions All authors were involved in the design of the study. LK, FJ, BLW, and IMVdL performed the data analyses. LK and IMVdL drafted the manuscript. All authors critically revised the manuscript, and read and approved the final manuscript.

Funding This work was supported by the Dutch Cancer Society under Grant VU 2013-5930.

Data availability The authors have full control of the data, and data is available upon request.

\section{Compliance with ethical standards}

Conflict of interest Dr. Verdonck-de Leeuw reported receiving grants from KWF Kankerbestrijding, ZonMw, Bristol-Myers Squibb. No other disclosures were reported.

Ethics approval The study was approved by the Medical Ethics Committee of VU University Medical Center.

Consent to participate All participants provided written informed consent.

Consent for publication All authors consented to publish this paper.

Code availability N.A.
Open Access This article is licensed under a Creative Commons Attribution 4.0 International License, which permits use, sharing, adaptation, distribution and reproduction in any medium or format, as long as you give appropriate credit to the original author(s) and the source, provide a link to the Creative Commons licence, and indicate if changes were made. The images or other third party material in this article are included in the article's Creative Commons licence, unless indicated otherwise in a credit line to the material. If material is not included in the article's Creative Commons licence and your intended use is not permitted by statutory regulation or exceeds the permitted use, you will need to obtain permission directly from the copyright holder. To view a copy of this licence, visit http://creativecommons.org/licenses/by/4.0/.

\section{References}

1. Jemal A, Bray F, Center MM, Ferlay J, Ward E, Forman D (2011) Global cancer statistics. CA Cancer J Clin 61:69-90

2. Blot WJ, McLaughlin JK, Winn DM, Austin DF, Greenberg RS, Preston-Martin S, Bernstein L, Schoenberg JB, Stemhagen A, Fraumeni JF Jr (1988) Smoking and drinking in relation to oral and pharyngeal cancer. Cancer Res 48:3282-3287

3. Pezzuto F, Buonaguro L, Caponigro F, Ionna F, Starita N, Annunziata C, Buonaguro FM, Tornesello ML (2015) Update on head and neck ancer: current knowledge on epidemiology, risk factors, Molecular Features and Novel Therapies. Oncology 89: $125-136$

4. Hashibe M, Brennan P, Chuang SC, Boccia S, Castellsague X, Chen C, Curado MP, Dal Maso L, Daudt AW, Fabianova E, Fernandez L, Wunsch-Filho V, Franceschi S, Hayes RB, Herrero R, Kelsey K, Koifman S, la Vecchia C, Lazarus P, Levi F, Lence JJ, Mates D, Matos E, Menezes A, McClean MD, Muscat J, Eluf-Neto J, Olshan AF, Purdue M, Rudnai P, Schwartz SM, Smith E, Sturgis EM, Szeszenia-Dabrowska N, Talamini R, Wei Q, Winn DM, Shangina O, Pilarska A, Zhang ZF, Ferro G, Berthiller J, Boffetta $P$ (2009) Interaction between tobacco and alcohol use and the risk of head and neck cancer: pooled analysis in the international head and neck cancer epidemiology consortium. Cancer Epidemiol Biomark Prev 18:541-550

5. Leemans CR, Braakhuis BJ, Brakenhoff RH (2011) The molecular biology of head and neck cancer. Nat Rev Cancer 11:9-22

6. Gooi Z, Chan JY, Fakhry C (2016) The epidemiology of the human papillomavirus related to oropharyngeal head and neck cancer. Laryngoscope 126:894-900

7. Ragin CC, Taioli E (2007) Survival of squamous cell carcinoma of the head and neck in relation to human papillomavirus infection: review and meta-analysis. Int J Cancer 121:1813-1820

8. Ang KK, Harris J, Wheeler R, Weber R, Rosenthal DI, NguyenTân PF, Westra WH, Chung CH, Jordan RC, Lu C, Kim H, Axelrod R, Silverman CC, Redmond KP, Gillison ML (2010) Human papillomavirus and survival of patients with oropharyngeal cancer. N Engl J Med 363:24-35

9. Fakhry C, Westra WH, Li S, Cmelak A, Ridge JA, Pinto H, Forastiere A, Gillison ML (2008) Improved survival of patients with human papillomavirus-positive head and neck squamous cell carcinoma in a prospective clinical trial. J Natl Cancer Inst 100: 261-269

10. Lindel K, Beer KT, Laissue J, Greiner RH, Aebersold DM (2001) Human papillomavirus positive squamous cell carcinoma of the oropharynx: a radiosensitive subgroup of head and neck carcinoma. Cancer 92:805-813

11. Rosenthal DI, Harari PM, Giralt J et al (2016) Association of human papillomavirus and p16 status with outcomes in the IMCL-9815 
phase III registration trial for patients with locoregionally advanced oropharyngeal squamous cell carcinoma of the head and neck treated with radiotherapy with or without cetuximab. J Clin Oncol 34: $1300-1308$

12. Høxbroe Michaelsen H, Grønhøj C, Høxbroe Michaelsen J, Friborg J, von Buchwald C (2017) Quality of life in survivors of oropharyngeal cancer: a systematic review and meta-analysis of 1366 patients. Eur J Cancer 78:91-102

13. Dodd RH, Waller J, Marlow LA (2016) Human papillomavirus and head and neck cancer: psychosocial impact in patients and knowledge of the link - a systematic review. Clin Oncol (R Coll Radiol) 28(7):421-439

14. Sharma A, Mendez E, Yueh B et al (2012) Human papillomaviruspositive oral cavity and oropharyngeal cancer patients do not have better quality-of-life trajectories. Otolaryngol Head Neck Surg 146: 739-745

15. Dziegielewski PT, Teknos TN, Durmus K, Old M, Agrawal A, Kakarala K et al (2013) Transoral robotic surgery for oropharyngeal cancer: long-term quality of life and functional outcomes. JAMA Otolaryngol Head Neck Surg 139(11):1099e108

16. Broglie MA, Soltermann A, Haile SR, Röösli C, Huber GF, Schmid S, Stoeckli SJ (2013) Quality of life of oropharyngeal cancer patients with respect to treatment strategy and p16-positivity. Laryngoscope 123:164-170

17. Ringash J, Fisher R, Peters L, Trotti A, O'Sullivan B, Corry J, Kenny L, van den Bogaert W, Wratten C, Rischin D (2017) Effect of p16 status on the quality-of-life experience during chemoradiation for locally advanced oropharyngeal cancer: a substudy of randomized trial trans-Tasman radiation oncology group (TROG) 02.02 (HeadSTART). Int J Radiat Oncol Biol Phys 97:678-686

18. Spinato G, Stellin M, Azzarello G, Bonazza D, Zanconati F, Politi D, Cocuzza S, Di Mauro P, Ausoni S, Tonoli G, Costantini G, Maiolino L, Spinato R, Da Mosto MC, Baboci L, Del Mistro A, Serra A, Tirelli G (2017) Multicenter research into the quality of life of patients with advanced oropharyngeal carcinoma with long-term survival associated with human papilloma virus. Oncol Lett 14(1): 185-193

19. Maxwell JH, Mehta V, Wang H, Cunningham D, Duvvuri U, Kim S, Johnson J, Ferris RL (2014) Quality of life in head and neck cancer patients: impact of HPV and primary treatment modality. Laryngoscope 124:1592-1597

20. Singh AK, Kushwaha JK, Anand A, Sonkar AA, Husain N, Srivastava K, Singh S (2016) Human papilloma virus in Oral cavity Cancer and relation to change in quality of life following treatmenta pilot study from northern India. Indian J Surg Oncol 7(4):386391

21. Xiao C, Zhang Q, Nguyen-Tân PF, List M, Weber RS, Ang KK, Rosenthal D, Filion EJ, Kim H, Silverman C, Raben A, Galloway T, Fortin A, Gore E, Winquist E, Jones CU, Robinson W, Raben D, Le QT, Bruner D (2017) Quality of Life and performance status from a substudy conducted within a prospective phase 3 randomized trial of concurrent standard radiation versus accelerated radiation plus cisplatin for locally advanced head and neck carcinoma: NRG Oncology RTOG 0129. Int J Radiat Oncol Biol Phys 97(4): 667-677

22. Marzouki HZ, Biron VL, Dziegielewski PT, Ma A, Vaz J, Constantinescu G, Harris J, O'Connell D, Seikaly H (2018) The impact of human papillomavirus (HPV) status on functional outcomes and quality of life (QOL) after surgical treatment of oropharyngeal carcinoma with free-flap reconstruction. J Otolaryngol Head Neck Surg 47(1):58
23. Xiao C, Beitler JJ, Higgins KA, Glazer T, Huynh LK, Paul S, Felger JC, Wommack EC, Saba NF, Shin DM, Bruner DW, Miller AH (2018) Associations among human papillomavirus, inflammation, and fatigue in patients with head and neck cancer. Cancer. 124(15):3163-3170

24. Takes RP, Rinaldo A, Silver CE, Piccirillo JF, Haigentz M Jr, Suárez C, van der Poorten V, Hermans R, Rodrigo JP, Devaney KO, Ferlito A (2010) Future of the TNM classification and staging system in head and neck cancer. Head Neck 32:1693-1711

25. Piccirillo JF (2000) Impact of comorbidity and symptoms on the prognosis of patients with oral carcinoma. Arch Otolaryngol Head Neck Surg 126:1086-1088

26. Rietbergen MM, Leemans CR, Bloemena E, Heideman DAM, Braakhuis BJM, Hesselink AT, Witte BI, de Jong RJB, Meijer CJLM, Snijders PJF, Brakenhoff RH (2013) Increasing prevalence rates of HPV attributable oropharyngeal squamous cell carcinomas in the Netherlands as assessed by a validated test algorithm. Int $\mathrm{J}$ Cancer 132:1565-1571

27. Duman-Lubberding S, van Uden-Kraan CF, Jansen F, Witte BI, Eerenstein SEJ, van Weert S, de Bree R, Leemans CR, Verdonckde Leeuw IM (2017) Durable usage of patient reported outcome measures in clinical practice to monitor health related quality of life in head and neck cancer patients. Support Care Cancer 25:37753783

28. Aaronson NK, Ahmedzai S, Bergman B et al (1993) The European Organization for Research and Treatment of Cancer QLQ-C30: a quality-of-life instrument for use in international clinical trials in oncology. J Natl Cancer Inst 85:365-376

29. Fayers P, Bottomley A, Group EQoL et al (2002) Quality of life research within the EORTC-the EORTC QLQ-C30. European Organisation for Research and Treatment of Cancer. Eur J Cancer 38(Suppl 4):S125-S133

30. Bjordal K, Ahlner-Elmqvist M, Tollesson E et al (1994) Development of a European Organization for Research and Treatment of Cancer (EORTC) questionnaire module to be used in quality of life assessments in head and neck cancer patients. EORTC Quality of Life Study Group. Acta Oncol 33:879-885

31. ter Wee MM, Lissenberg-Witte BI (2019) A quick guide on how to conduct medical research - from set-up to publication

32. Judy GD, Green R, Aumer SL, Amdur RJ, Tan X, Sheets N, Weissler M, Zanation A, Patel S, Hackman T, Mendenhall WM, Chera BS (2018) Preservation of swallowing function with deintensified chemoradiation therapy for HPV-associated oropharyngeal squamous cell carcinoma. Adv Radiat Oncol 3(3):356-365

33. Chera BS, Amdur RJ, Tepper JE, Tan X, Weiss J, Grilley-Olson JE, Hayes DN, Zanation A, Hackman TG, Patel S, Sheets N, Weissler MC, Mendenhall WM (2018) Mature results of a prospective study of deintensified chemoradiotherapy for low-risk human papillomavirus-associated oropharyngeal squamous cell carcinoma. Cancer. 124(11):2347-2354

34. Hegde JV, Shaverdian N, Daly ME, Felix C, Wong DL, Rosove $\mathrm{MH}$, Garst JH, Wang PC, Veruttipong D, Rao S, Fragoso RC, Riess JW, Steinberg ML, Chen AM (2018) Patient-reported quality-oflife outcomes after de-escalated chemoradiation for human papillomavirus-positive oropharyngeal carcinoma: findings from a phase 2 trial. Cancer. 124(3):521-529

Publisher's note Springer Nature remains neutral with regard to jurisdictional claims in published maps and institutional affiliations. 